\title{
Morphing tree structures for latent thermal energy storage
}

S. Ziaei, , S. Lorente, and, and A. Bejan

Citation: Journal of Applied Physics 117, 224901 (2015); doi: 10.1063/1.4921442

View online: http://dx.doi.org/10.1063/1.4921442

View Table of Contents: http://aip.scitation.org/toc/jap/117/22

Published by the American Institute of Physics

\section{Articles you may be interested in}

The $S$ curve of energy storage by melting

Journal of Applied Physics 116, 114902 (2014); 10.1063/1.4894869

Distributed energy storage: Time-dependent tree flow design

Journal of Applied Physics 119, 184901 (2016); 10.1063/1.4948663

Constructal law of design and evolution: Physics, biology, technology, and society

Journal of Applied Physics 113, 151301 (2013); 10.1063/1.4798429

AlP $\left.\right|_{\text {Applied Physics }} ^{\text {Jounnal of }}$

Save your money for your research.

It's now FREE to publish with us -

no page, color or publication charges apply.
Publish your research in the

Joumal of Applied Physics

to claim your place in applied

physics history. 


\title{
Morphing tree structures for latent thermal energy storage
}

\author{
S. Ziaei, ${ }^{1}$ S. Lorente, ${ }^{2}$ and A. Bejan ${ }^{1}$ \\ ${ }^{1}$ Department of Mechanical Engineering and Materials Science, Duke University, Durham, \\ North Carolina 27708-0300, USA \\ ${ }^{2}$ INSA, Université de Toulouse, 135 Avenue de Rangueil, Toulouse 31077, France
}

(Received 31 March 2015; accepted 9 May 2015; published online 9 June 2015)

\begin{abstract}
Here, we report the numerical study of time dependent storage of energy by melting a phase change material. The heating is provided along invading lines, which change from single-line invasion to tree-shaped invasion. The numerical simulations show that the history of the amount of melted material is S-shaped. We also found that the fastest melting (i.e., the steepest $\mathrm{S}$ curve) is discovered by allowing the tree architecture to morph freely, toward greater access over time. The stem length and branching angle of invading trees can be selected such that the complete melting process is shorter. The melting process can also be made faster by increasing the complexity of the tree structure. (C) 2015 AIP Publishing LLC. [http://dx.doi.org/10.1063/1.4921442]
\end{abstract}

\section{INTRODUCTION}

The phenomenon of design generation and evolution in the nature and engineering is described by the constructal law, ${ }^{1}$ which accounts for the universal tendency of freely morphing flow systems to generate configurations that evolve toward greater access for their currents. ${ }^{2,3}$ The evolutionary designs that emerge naturally are tree-shaped when the tendency of the flow is to flow more easily between areas (or volumes) and discrete points. ${ }^{4-18}$ An important contemporary application of the tree-shaped design is in the energy storage systems. ${ }^{19-22}$

The fundamentals of heat transfer in phase change material (PCM) have attracted considerable attention because of the potential use of phase change processes in energy storage applications. $^{23-35}$ In Ref. 31, we studied theoretically the melting process that occurs inside the phase change material cavity heated by lines of higher temperature (see Fig. 1). We showed that the amount of melted material increases in time as a function that resembles an S. Unlike in Ref. 31, where the invading line was prescribed and held fixed (one straight line, or a rigid tree), in the present article, the invading pattern is free to change. We use this freedom in order to discover numerically the tree design features that underpin the steepest S-curve, i.e., the fastest spreading of heat from tree designs. The tree architecture discovered in this manner is more efficient, in the sense that it accelerates the melting of the material throughout the volume.

\section{MODEL}

The square domain of side $L=0.001 \mathrm{~m}$ is filled with a phase change material, which is isothermal and solid at its melting temperature $T_{0}=303 \mathrm{~K}$. The outer surface of the enclosure is adiabatic. The source of heat is one invading line of higher temperature $T_{1}=353 \mathrm{~K}$, which can be continued by branches. The tips advance with the constant speed $V=0.001 \mathrm{~m} / \mathrm{s}$ (Fig. 1).

Heat is initially transferred by diffusion perpendicularly to the invading lines. Later, after the invading line reaches the boundary of the domain, heat continues to be diffused perpendicularly to the line, and the melting process continues. Heat conduction in the liquid PCM is governed by the energy equation

$$
\rho c_{P} \frac{\partial T}{\partial t}=k \nabla^{2} T
$$

where $\rho, c_{P}$, and $k$ are the density, specific heat, and thermal conductivity of the PCM. These properties are assumed to be the same in liquid and solid states, and are listed in Table I.

The first law of thermodynamics for the control volume of zero thickness that encloses the melting front (liquid-solid interface) requires

$$
\rho L_{f} \frac{\partial \delta}{\partial t}=k \frac{\partial T}{\partial y}
$$

in which $L_{\mathrm{f}}$ is the PCM latent heat of fusion and $\delta$ is the melt layer thickness. The right-hand side of this equation expresses the difference between the heat flux delivered by the liquid boundary layer and the heat flux absorbed by that layer. This difference is balanced by the enthalpy absorbed during melting at the liquid-solid interface. When the melt layer is thin enough, the temperature variation across it is linear, and Eq. (2) becomes

$$
\rho L_{f} \frac{\partial \delta}{\partial t}=k \frac{T_{1}-T_{0}}{\delta} .
$$

Equation (3) yields the scale of the melt layer thickness

$$
\delta \sim\left[\frac{k\left(T_{1}-T_{0}\right) t}{\rho L_{f}}\right]^{1 / 2} .
$$

This relation suggests that the layers of liquid formed on both sides of the advancing lines cover the territory at a particular time. The objective is to determine the best configuration of the paths of the invading lines such that the complete melting of the PCM can be made faster. 


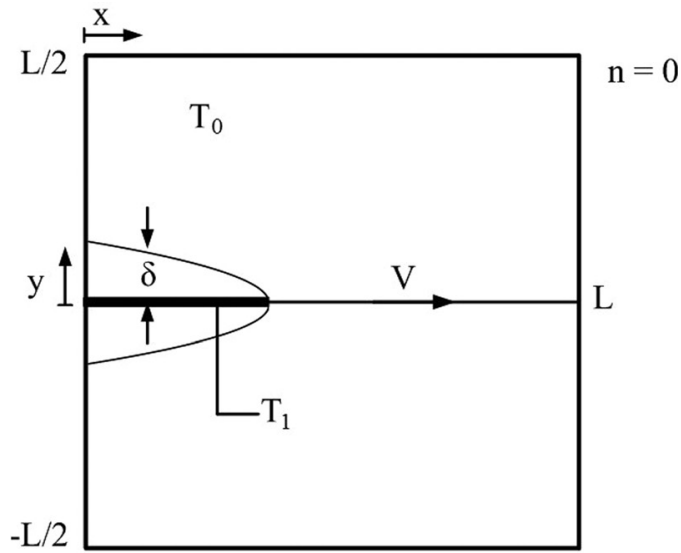

(a)

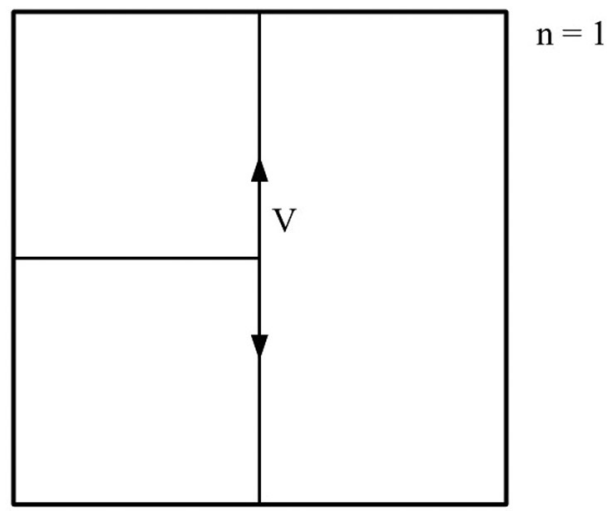

(b)

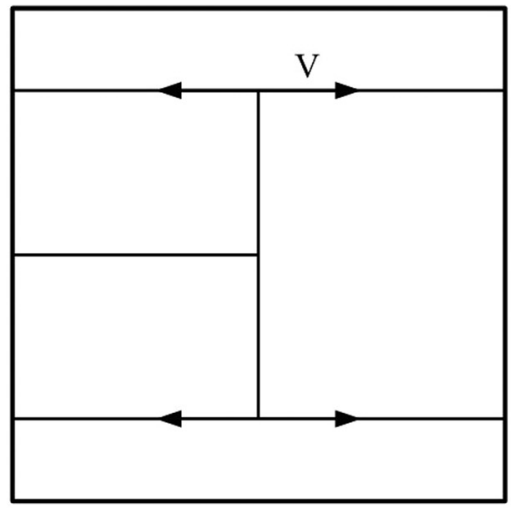

(c)

FIG. 1. Tree-shaped line invasion of a domain filled with PCM, with assumed T-shaped bifurcations.

In this study, the phase change problem is solved using the effective heat capacity method. ${ }^{36,37}$ Assuming that the PCM melts between $T_{0}$ and $T_{0}+\tau$, we write that the specific heat is

$$
c_{P}^{*}=c_{P}+\frac{L_{f}}{\tau} .
$$

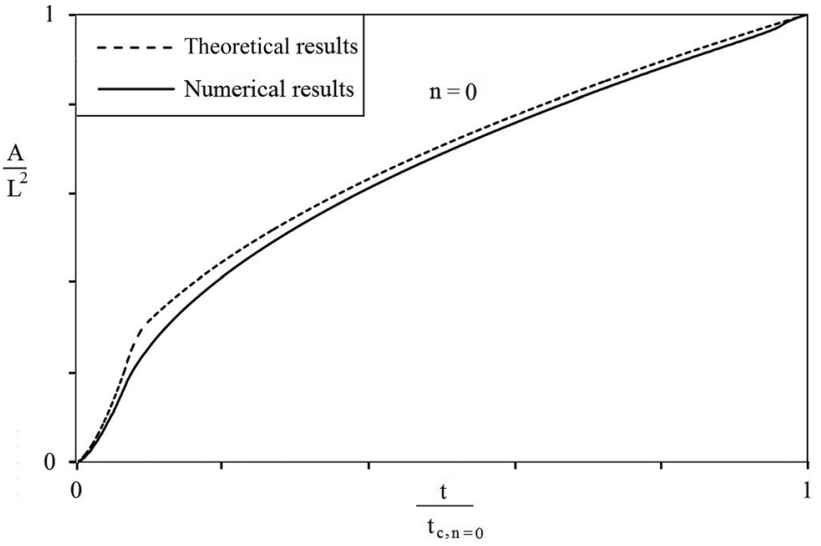

FIG. 2. Comparison between the theoretical and numerical results of the melting history when $\mathrm{n}=0$.

Below $T_{0}$ and above $T_{0}+\tau$, the specific heat has the value given in Table I. Computations were performed by using a finite element package. ${ }^{38}$ The mesh of the domain was refined by increasing the number of mesh elements by a factor of 5 until the melting fraction (area of the melted PCM divided by the domain area) as the function of time change by less than $0.5 \%$, i.e., until the solution is mesh independent.

\section{T-SHAPED TREES}

The first set of simulations concerns the case when the two branches are collinear, i.e., the tree is dichotomous with T-shaped bifurcations, which are fixed (Fig. 1). The tree lines have almost zero thicknesses, and $\mathrm{n}$ represents the levels of bifurcation, such that $\mathrm{n}=0$ corresponds to the tree with one stem and no branches. This configuration is considered as a reference in the search for faster melting designs.

In the theoretical study of this phenomenon, ${ }^{31}$ the PCM in the domain of Fig. 1 was melted by the thermal diffusion during two distinct processes, invasion followed by consolidation. The two processes, together, account for the S shape of the history curve, cf. Fig. 2. According to Eq. (4), the melt layer thickness during invasion has a parabolic shape in time, and therefore, the instantaneous enclosed area is

$$
A_{i}=\frac{2}{3} 2 \delta V t
$$

and after combining with Eq. 4, we concluded that

$$
A_{i} \sim A_{i, \text { end }}\left(\frac{t}{t_{\text {in }}}\right)^{3 / 2}
$$

where

TABLE I. Thermophysical properties of the PCM.

\begin{tabular}{lccccc}
\hline \hline $\begin{array}{l}\text { Density, } \rho \\
\left(\mathrm{kg} / \mathrm{m}^{3}\right)\end{array}$ & $\begin{array}{c}\text { Thermal conductivity, } \\
k(\mathrm{~W} / \mathrm{m} \mathrm{K})\end{array}$ & $\begin{array}{c}\text { Specific heat } \\
\text { at constant pressure, } c_{P}(\mathrm{~kJ} / \mathrm{kg} \mathrm{K})\end{array}$ & $\begin{array}{c}\text { Latent heat of } \\
\text { fusion, } L_{f}(\mathrm{~J} / \mathrm{kg})\end{array}$ & $\begin{array}{c}\text { Melting temperature, } \\
T_{0}(\mathrm{~K})\end{array}$ & $\begin{array}{c}\text { Melting temperature } \\
\text { range, } \tau(\mathrm{K})\end{array}$ \\
\hline 800 & 0.2 & 1.25 & 125,000 & 303 & 0.5 \\
\hline
\end{tabular}




$$
t_{\text {in }}=\frac{L}{V} \quad A_{i, \text { end }} \sim \frac{4}{3}\left(\frac{a}{V}\right)^{1 / 2} L^{3 / 2} a=\frac{2 k\left(T_{1}-T_{0}\right)}{\rho L_{f}} .
$$

Repeating the same procedure, we discovered that the swept area by consolidation increases in proportion with time raised to the power $1 / 2$

$$
A_{c} \sim L^{2}\left(\frac{t-t_{\text {in }}}{t_{c}}\right)^{1 / 2}
$$

where $\mathrm{L}^{2}$ is the total area, and

$$
t_{c} \sim \frac{L^{2}}{4 a} .
$$

The growth of melted material during the consolidation is slower than the growth during the invasion process, and this explains the inflexion of the S-curve. In Ref. 31, we found that faster melting occurs as the number of bifurcation level increases. For instance, adding two levels of pairing speeded up the melting duration by $75 \%$ compared with the configuration of a single tree, thus confirming our expectation of a steeper S-curve. In the present study, numerical simulations were performed in order to demonstrate the validity of the theoretical results summarized here. Plotted in Fig. 2 is the evolution of melting process predicted by the theory, Eqs. (7) and (9), and obtained from the simulation when $n=0$. The agreement between the predicted and the observed proves the S-shaped history of the time-dependent storage system.

Further support for the theory is provided by the graph of Fig. 3, which depicts the melting fraction as functions of time when $\mathrm{n}=0,1$, and 2 are all invading the material at the same speed. The abscissa parameter is the melting time of each tree configuration relative to the complete melting time of $n=0$ configuration $\left(t_{c, n=0}\right)$. The steeper parts of S-curves account for invasion phases that are proportional to $\mathrm{t}^{3 / 2}$. In accord with the theory, the tree-shaped invading lines make the approach to the complete melting more rapid, along a steeper S-curve. This effect is understandable, because the evolutionary design is accompanied by increase in the invasion lengths.

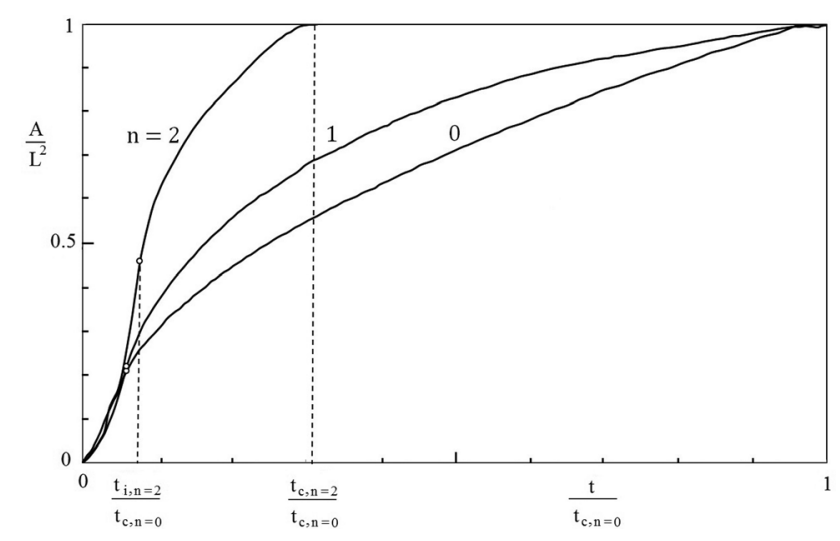

FIG. 3. The effect of the number of bifurcation levels on the shape of the Scurve.

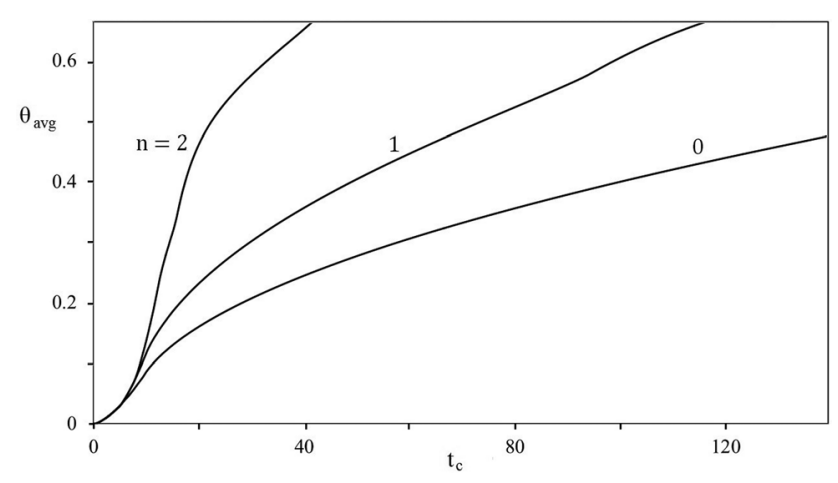

FIG. 4. The effect of complexity (n) on the evolution of the average temperature.

Figure 4 illustrates the evolution of $\theta_{\mathrm{av}}\left(\mathrm{t}_{\mathrm{c}}\right)$ toward equilibrium between the solid PCM and the invading lines of higher temperature $\left(\theta_{\mathrm{av}}=1\right)$. For each configuration, Fig. 4 displays only the portion of the curve that represents the time interval over which the material melts completely. The dimensionless temperature averaged over the domain is defined as

$$
\theta_{a v}=\frac{T_{a v}-T_{0}}{T_{1}-T_{0}} .
$$

It is shown that the $\theta_{\text {av }}\left(\mathrm{t}_{\mathrm{c}}\right)$ curves are also $\mathrm{S}$-shaped and trees with greater levels of complexity accelerate the arrival of equilibrium.

In the assumed design of Fig. 1(b), the invading line bifurcates once at half of the side of the domain. We now assess the effect of stem length on the performance of melting process by simulating the melting process in several $\mathrm{T}$-shaped configurations with different stem length ratios $\mathrm{L}_{\mathrm{s}} / \mathrm{L}$ while other conditions remain unchanged. The design conclusion is that the optimal stem length is in the vicinity of $0.6 \mathrm{~L}$ (see Fig. 5 ). It is worth mentioning that all the numbers with reported dimensions (e.g., units of time and angle), for the sake of comparison, are obtained based on the properties listed in Table I and cannot be applied to other materials.

The question addressed in Secs. IV and V is whether the melting process can be accelerated further even when the number of bifurcation levels (n) is fixed.

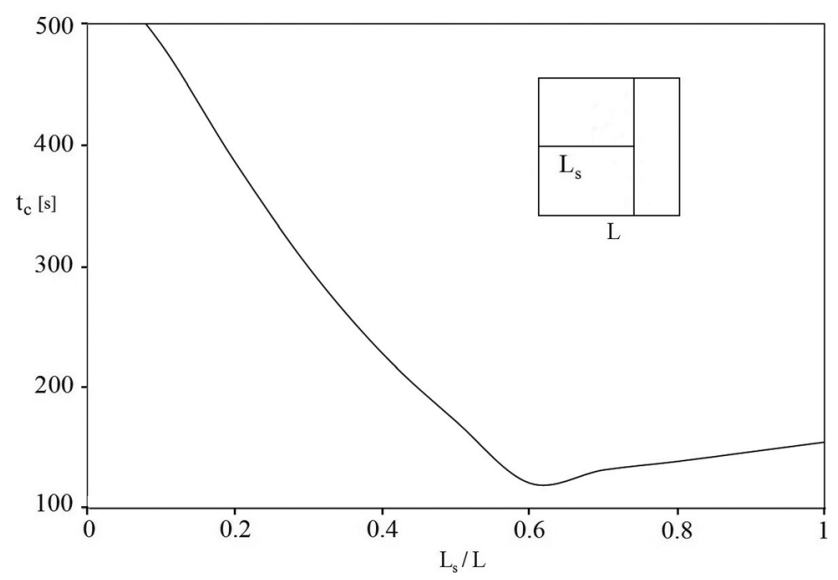

FIG. 5. The effect of the stem length ratio on the rate of melting process for the T-shaped tree with one level of branching. 


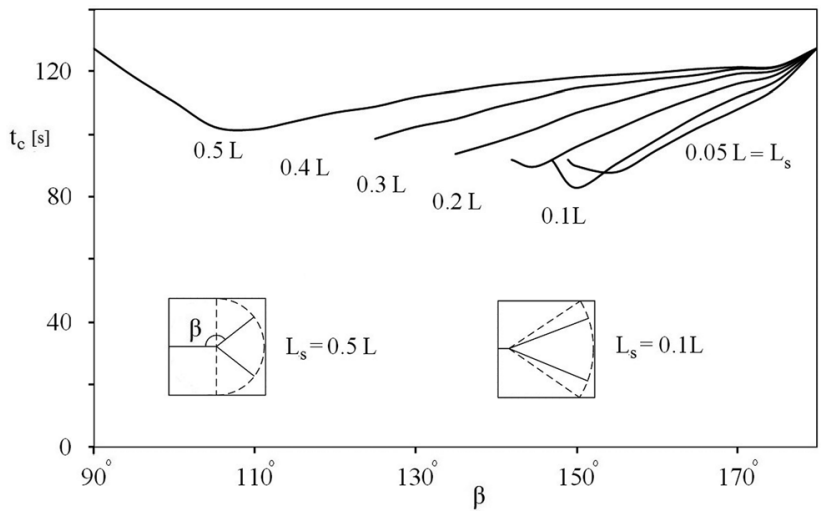

FIG. 6. The effect of the bifurcation angle $\beta$ on the complete melting time for different stem length ratios.
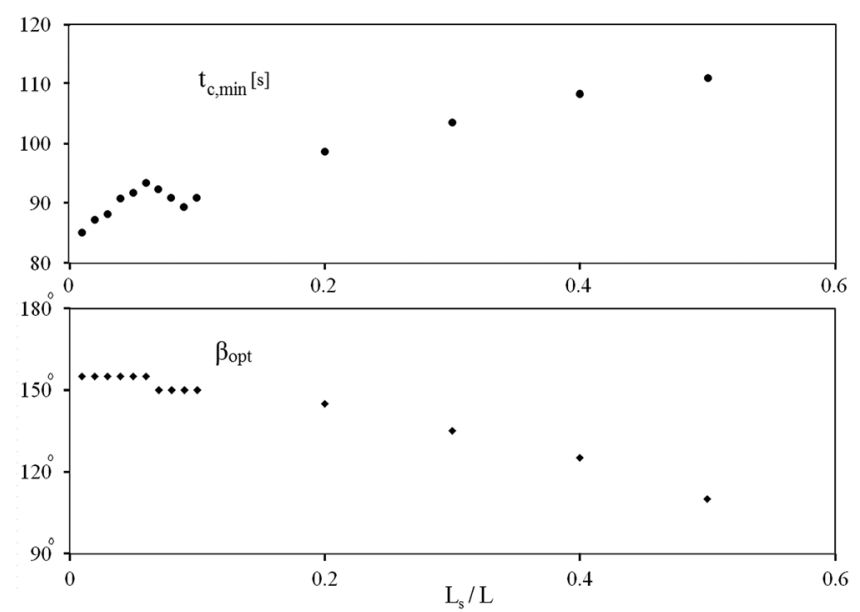

FIG. 7. The Optimal bifurcation angle $\beta_{\text {opt }}$ and the shortest melting time as function of stem length ratio.

\section{Y-SHAPED TREES}

According to the constructal law, the better flow configurations are those that facilitate flow access. This can be achieved by endowing the configurations with more degrees of freedom. In the case of one level of branching, we allow the tree geometry to morph freely. Therefore, we varied not only the stem length but also the bifurcation angle of the Y-shaped configuration in the presence of one bifurcation level.

The objectives of the simulations in this section were to illustrate the existence of an optimal invading line configuration for the shortest duration of melting process. These results are plotted in Fig. 6 that compares on the same basis the complete melting duration of tree architectures with freely varying angles. On the same basis means that all the configurations have the same invasion length, meaning holding the total length of stem and branch fixed and equal to L. By doing so, some configurations could not be tested for all the angles in the range of $90^{\circ}$ to $180^{\circ}$. As shown in this figure, the minimum of $0.1 \mathrm{~L}$ curve is the lowest, and its corresponding angle is $150^{\circ}$.

Figure 7 is a summary of the optima determined in Fig. 6, which shows the optimal bifurcation angles of smaller stem length ratios. More precisely, the stem length ratio of 0.01 with the bifurcation angle of $155^{\circ}$ yields the most efficient melting process when $n=1$. This numerically optimized architecture reduced the complete melting duration by $40 \%$ relative to the assumed $\mathrm{T}$-shaped structure. The conclusion is that the freely varying bifurcation is a beneficial feature for the purpose of accelerating the melting process.

The rate of melting process also depends on the Peclet number, which is the ratio of the time of thermal diffusion perpendicular to the invading line $\left(\mathrm{L}^{2} / \alpha\right)$ divided by the time of line invasion (L/V), where $\alpha$ is the thermal diffusivity of the PCM. This dimensionless number has the initial value of 50 in our study. Figure 8 illustrates the effect of Pe on the evolution of the temperature of the PCM. The dark blue represents the solid, and the rest shows the melted material at different temperatures when $\mathrm{Pe}=50$ and 5000. It can be seen that the faster tree-shaped design offers a larger melted territory at this specific moment $\left(\tilde{\mathrm{t}}=0.2=\alpha \mathrm{t} / \mathrm{L}^{2}\right)$.

The high Peclet number and the optimal branching of the invading lines have the effect of accelerating the melting process. Figure 9 shows a comparison between two cases that offer the same overall melting time: one-line invasion at high Pe, versus optimized Y-shaped invasion at much lower Pe. This comparison underlines the effect of morphing the design (one-line vs $\mathrm{Y}$-shape) in accelerating the melting process when the PCM and the invasion speed are fixed.

\section{CONCLUSIONS}

In this paper, we studied numerically the process of phase-change energy storage in a domain in which the invading lines of higher temperature are free to morph. We started with the assumed arrangements of Fig. 1 that serve as a base of more complicated design configurations. The numerical results showed that the amount of melted material and the average temperature have the S-shaped histories, in accordance with the theoretical predictions.

The objective was to determine the layout of the invading lines over the territory, such that the time needed to melt

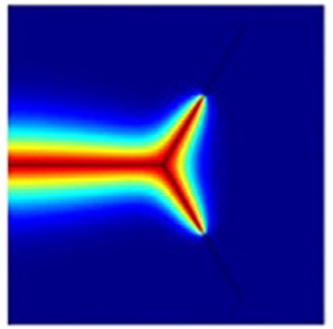

$\mathrm{Pe}=50$

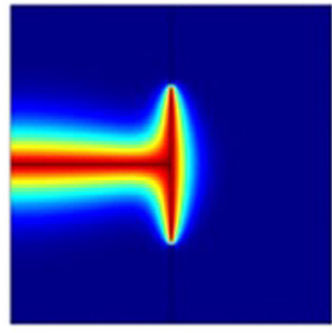

$\mathrm{Pe}=50$

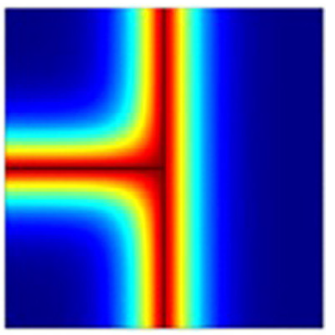

$\mathrm{Pe}=5000$
FIG. 8. The effect of the line invasion speed $(\mathrm{Pe})$ on the melting fraction at the time $\tilde{\mathrm{t}}=0.03$. 


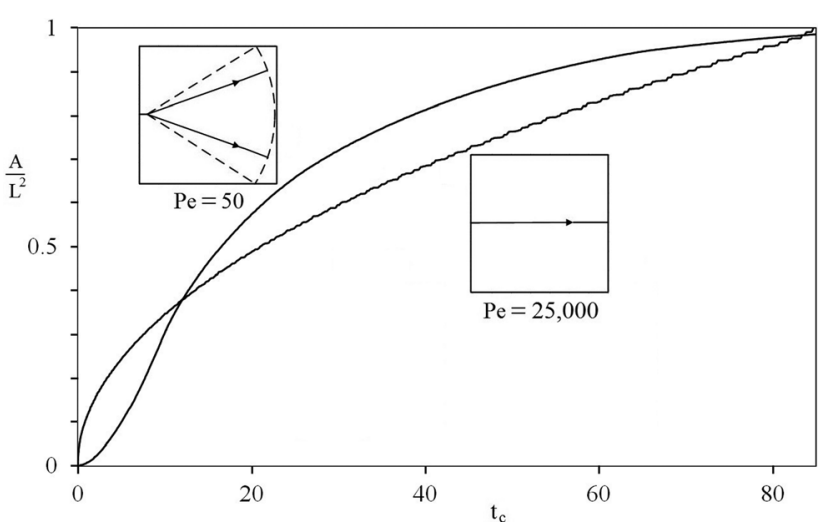

FIG. 9. Comparison between the melting history of the optimized Y-shaped configuration and its single-line invasion equivalent at a much higher Peclet number.

the material entirely is the shortest. We showed that a steeper $\mathrm{S}$ curve is achieved by increasing the freedom to morph for the flow architecture. Therefore, we explored the impact of parameters such as the number of bifurcation levels, size of the stem length, bifurcation angle, and the Peclet number on the melting fraction curve. We found that increasing the number of branching levels and the Peclet number yields a more rapid melting process. The optimized flow architecture was discovered by varying simultaneously the branching angle and the stem length in the tree structure with one branch. The chief conclusion is that adding more freedom for a design to morph leads to better performance.

\section{ACKNOWLEDGMENTS}

The work of Professor Bejan and Professor Lorente was supported by a grant from the National Science Foundation.

${ }^{1}$ A. Bejan, Advanced Engineering Thermodynamics, 2nd ed. (Wiley, New York, 1997).

${ }^{2}$ A. Bejan and S. Lorente, "Constructal law of design and evolution: Physics, biology, technology and society," J. Appl. Phys. 113, 151301 (2013).

${ }^{3}$ A. Bejan and S. Lorente, Design with Constructal Theory (Wiley, Hoboken, NJ, 2008).

${ }^{4}$ W. Wechsatol, S. Lorente, and A. Bejan, "Optimal tree-shaped networks for fluid flow in a disc-shaped body," Int. J. Heat Mass Transfer 45, 4911-4924 (2002).

${ }^{5}$ L. Combelles, S. Lorente, R. Anderson, and A. Bejan, "Tree-shaped fluid flow and heat storage in a conducting solid," J. Appl. Phys. 111, 014902 (2012).

${ }^{6}$ S. Lorente, W. Wechsatol, and A. Bejan, "Tree-shaped flow structures designed by minimizing path lengths," Int. J. Heat Mass Transfer 45, 3299-3312 (2002).

${ }^{7}$ A. Bejan and S. Lorente, "Constructal tree-shaped flow structures," Appl. Therm. Eng. 27, 755-761 (2007).

${ }^{8} \mathrm{M}$. Almogbel and A. Bejan, "Constructal optimization of nonuniformly distributed tree-shaped flow structures for conduction," Int. J. Heat Mass Transfer 44, 4185-4194 (2001).

${ }^{9}$ W. Wechsatol, S. Lorente, and A. Bejan, "Tree-shaped insulated designs for the uniform distribution of hot water over an area," Int. J. Heat Mass Transfer 44, 3111-3123 (2001).

${ }^{10} \mathrm{~W}$. Wechsatol, S. Lorente, and A. Bejan, "Development of tree-shaped flows by adding new users to existing networks of hot water pipes," Int. J. Heat Mass Transfer 45, 723-733 (2002).

${ }^{11}$ S. Lorente and A. Bejan, "Svelteness, freedom to morph, and constructal multi-scale flow structures," Int. J. Therm. Sci. 44, 1123-1130 (2005).
${ }^{12}$ V. D. Zimparov, A. K. da Silva, and A. Bejan, "Constructal tree-shaped parallel flow heat exchangers," Int. J. Heat Mass Transfer 49, 4558-4566 (2006).

${ }^{13}$ C. Zamfirescu and A. Bejan, "Constructal tree-shaped two-phase flow for cooling a surface,” Int. J. Heat Mass Transfer 46, 2785-2797 (2003).

${ }^{14}$ V. Arion, A. Cojocari, and A. Bejan, "Constructal tree shaped networks for the distribution of electrical power," Energy Convers. Manage. 44, 867-891 (2003).

${ }^{15}$ A. Bejan, L. A. O. Rocha, and S. Lorente, "Thermodynamic optimization of geometry: T- and Y-shaped constructs of fluid streams," Int. J. Therm. Sci. 39, 949-960 (2000).

${ }^{16}$ W. Wechsatol, A. Bejan, and S. Lorente, "Tree-shaped flow architectures: Strategies for increasing optimization speed and accuracy," Numer. Heat Transfer 48, 731-744 (2005).

${ }^{17}$ S. Lorente, W. Wechsatol, and A. Bejan, "Optimization of tree-shaped flow distribution structures over a disc-shaped area," Int. J. Energy Res. 27, 715-723 (2003).

${ }^{18}$ A. K. da Silva, S. Lorente, and A. Bejan, "Constructal multi-scale treeshaped heat exchangers," J. Appl. Phys. 96, 1709-1718 (2004).

${ }^{19}$ C. Zamfirescu and A. Bejan, "Tree-shaped structures for cold storage," Int. J. Refrig. 28, 231-241 (2005).

${ }^{20}$ A. Bejan, "Constructal tree-shaped paths for conduction and convection," Int. J. Energy Res. 27, 283-299 (2003).

${ }^{21}$ D. H. Kang, S. Lorente, and A. Bejan, "Constructal dendritic configuration for the radiation heating of a solid stream," J. Appl. Phys. 107, 114910 (2010).

${ }^{22}$ A. Bejan, S. Lorente, and D. H. Kang, "Constructal design of regenerators,” Int. J. Energy Res. 37, 1509-1518 (2013).

${ }^{23}$ A. Abhat, "Low temperature latent heat thermal energy storage: Heat storage materials," Sol. Energy 30, 313-332 (1983).

${ }^{24}$ R. Velraj, R. V. Seeniraj, B. Hafner, C. Faber, and K. Schwarzer, "Heat transfer enhancement in a latent heat storage system," Sol. Energy 65, 171-180 (1999).

${ }^{25}$ E. B. S. Mettawee and G. M. R. Assassa, "Thermal conductivity enhancement in a latent heat storage system," Sol. Energy 81, 839-845 (2007).

${ }^{26}$ M. Costa, D. Buddhi, and A. Oliva, "Numerical simulation of a latent heat thermal energy storage system with enhanced heat conduction," Energy Convers. Manage. 39, 319-330 (1998).

${ }^{27}$ K. A. R. Ismail and J. R. Henriquez, "Numerical and experimental study of spherical capsules packed bed latent heat storage system," Appl. Therm. Eng. 22, 1705-1716 (2002).

${ }^{28}$ N. Nallusamy, S. Sampath, and R. Velraj, "Experimental investigation on a combined sensible and latent heat storage system integrated with constant/varying (solar) heat sources," Renewable Energy 32, 1206-1227 (2007).

${ }^{29}$ A. Koca, H. F. Oztop, T. Koyun, and Y. Varol, "Energy and exergy analysis of a latent heat storage system with phase change material for a solar collector," Renewable Energy 33, 567-574 (2008).

${ }^{30}$ N. K. Bansal and D. Buddhi, "An analytical study of a latent heat storage system in a cylinder,” Energy Convers. Manage. 33, 235-242 (1992).

${ }^{31}$ A. Bejan, S. Ziaei, and S. Lorente, "The S curve of energy storage by melting," J. Appl. Phys. 116, 114902 (2014).

${ }^{32}$ C. Charach and P. B. Kahn, "Transient phase-change heat transfer in finite bodies: Universal bounds for the solidification (melting) time," J. Appl. Phys. 59, 3579-3581 (1986).

${ }^{33}$ C. Charach and M. Conti, "Thermodynamics of latent heat storage in parallel or in series with a heat engine," J. Appl. Phys. 78, 1430-1437 (1995).

${ }^{34}$ M. Almajali, K. Lafdi, and S. Shaikh, "Interfacial and capillary pressure effects on the thermal performance of wax/foam composites," J. Appl. Phys. 102, 033506 (2007).

${ }^{35}$ S. Shaikh, K. Lafdi, and K. Hallinan, "Carbon nanoadditives to enhance latent heat storage of phase change materials," J. Appl. Phys. 103, 094302 (2008).

${ }^{36} \mathrm{~W}$. Ogoh and D. Groulx, "Effects of the number and distribution of fins on the storage characteristics of a cylindrical latent heat energy storage system: A numerical study," Heat Mass Transfer 48, 1825-1835 (2012).

${ }^{37}$ P. Lamberg, R. Lehtiniemi, and A. M. Henell, "Numerical and experimental investigation of melting and freezing processes in phase change material storage," Int. J. Therm. Sci. 43, 277-287 (2004).

${ }^{38}$ See http://www.comsol.com/ for information about COMSOL Multiphysics. 